\title{
Inversions in the factor VIII gene: improvement of carrier detection and prenatal diagnosis in Dutch haemophilia A families
}

Piëtte P Deutz-Terlouw, Monique Losekoot, Renske Olmer, W Cynthia Pieneman, Simone de Vries-v d Weerd, Ernest Briët, Egbert Bakker

\begin{abstract}
Haemophilia $A$ is an $X$ linked bleeding disorder caused by a heterogeneous spectrum of mutations in the factor VIII gene. It has recently been reported that about $50 \%$ of severe haemophilia $A$ cases are the result of an inversion in the factor VIII gene. The inversion results from homologous recombination between the $A$ gene located in intron 22 of the FVIII gene and one of the two distal $A$ genes, thus disrupting the coding sequence of the factor VIII gene. The inversion can be detected by conventional Southern blotting and hybridisation techniques. Here we present an analysis of 177 unrelated Dutch haemophilia $A$ cases for the presence of an inversion. In $57 \%$ of the patients with severe disease an inversion was found and also in at least one of the 26 patients with moderately severe disease. The majority of inversions ( $85 \%$ ) involved the most distal $A$ gene, while in a minority $(15 \%)$ the more proximal A gene was involved. We show that direct mutation detection greatly improves the assessment of carrier status and prenatal diagnosis for haemophilia $A$, especially in families with an isolated patient. The inversion is predominantly of grandpaternal origin.
\end{abstract}

(F Med Genet 1995;32:296-300)

Laboratory,

Wassenaarseweg 72 ,

2333 AL, Leiden,

The Netherlands

P P Deutz-Terlouw

M Losekoot

R Olmer

E Bakker

Haemostasis and

Thrombosis Research

Centre, Department of

Haematology,

Academic Hospital,

Leiden, The

Netherlands

W C Pieneman

E Briët

Clinical Genetic

Centre, Leiden

The Netherlands

P P Deutz-Terlouw

$M$ Losekoot

$\mathrm{R}$ Olmer

$S$ de Vries-v d Weerd

E Bakker

Correspondence to: Dr Losekoot.

Received 22 August 1994 Revised version accepted fo publication 21 November 1994 disorder (incidence approximately 1 in 10000 males), is caused by a deficiency of or an abnormality in coagulation factor VIII. It is a clinically very heterogeneous disorder; patients with $<1 \%, 1-5 \%$, and $5-20 \%$ factor VIII coagulant activity usually have severe, moderate, and mild disease respectively. ${ }^{1}$ In the Netherlands the relative frequencies of occurrence are approximately $40 \%$ for severe, $20 \%$ for moderate, and $40 \%$ for mild haemophilia. ${ }^{2}$ The coagulation factor VIII is encoded by the factor VIII (FVIII) gene, which spans $186 \mathrm{~kb}$, contains 26 exons, and encodes a $9 \mathrm{~kb}$ mRNA. ${ }^{3-5}$ Mutation analysis has shown a heterogeneous spectrum of mutations suggesting that almost every family bears its own mutation. ${ }^{6}$ However, in contrast to mild and moderate forms, in $50 \%$ of severe haemophilia A patients no mutation could be found until recently. ${ }^{7}$ Naylor $e t a l^{8}$ reported that in these patients RT-PCR across the boundary of exon 22 and exon 23 was not possible. At the end of 1993 both Lakich et al and Naylor et $a l^{10}$ reported that homologous recombination of the FVIII associated A gene, located in intron 22, with either of two A genes located $\sim 500 \mathrm{~kb}$ upstream leads to inversion of all intervening DNA and disruption of the FVIII gene. In this way the promoter and exons 1-22 are separated from, and in the opposite orientation to, exons 23-26. The latter part of the FVIII gene is still transcribed by the promoter of a gene (called gene B) also located in intron 22.

Until now, carrier detection and prenatal diagnosis in haemophilia A families has been almost entirely dependent on haplotype analysis by use of RFLP and CA repeat markers within or closely linked to the FVIII gene. ${ }^{11-13}$ The feasibility of a diagnosis with linked markers greatly depends on the overall heterozygosity of these markers as well as the availability and cooperation of family members. Furthermore, since one in three cases is the result of a de novo mutation, direct mutation analysis greatly increases the reliability of carrier detection in families with an isolated case of haemophilia A. The inversion as a cause of haemophilia $\mathrm{A}$ has been reported to be present in about $50 \%$ of patients with severe disease and can be detected in a relatively simple way (Southern blot analysis). ${ }^{910}$ Here we report the analysis of 177 unrelated Dutch haemophilia A patients. Both the presence and type of inversion in relation to the severity of the disorder are addressed. Furthermore, we discuss the impact of detection of the inversion on the overall informativity and accuracy of the genetic test for haemophilia A.

\section{Materials and methods}

Referrals were sent to us from centres all over The Netherlands. Coagulation assays and probability calculations were performed as previously described. ${ }^{14}{ }^{15}$ Total genomic DNA was extracted from peripheral blood according to standard methods. ${ }^{16}$ The inversions were detected by Southern blot analysis according to the following procedure: DNA was digested with $B c I$, electrophoresed on a $0.5 \%$ agarose gel for 36 hours, and transferred to a Hybond $\mathrm{N}^{+}$membrane. ${ }^{17}$ The F8A probe $(0.9 \mathrm{~kb}$ EcoRI SstI fragment plasmid p482.6, ATCC catalogue No 57203) was labelled with $10 \mu \mathrm{Ci} \alpha^{32} \mathrm{P}$ dCTP using the Amersham Megaprime labelhours at $65^{\circ} \mathrm{C}$ in NaPi/PEG buffer $(0.25 \mathrm{~mol} / 1$ ling kit. The membrane was hybridised for 16 


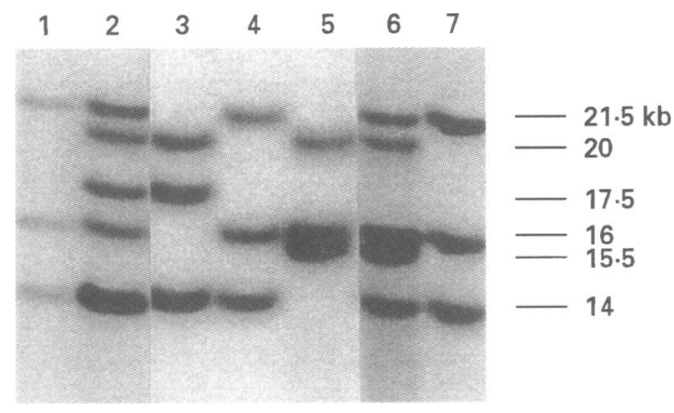

Figure 1 Southern blot analysis of patients and carriers with an inversion: pattern of a healthy male after digestion with BclI and hybridisation with the F8A probe (lanes 1,4 , and 7). A patient and carrier of inversion type 1 (recombination with most distal $A$ gene) are shown in lanes 3 and 2 respectively; a patient and a carrier of inversion type 2 (recombination with more proximal $A$ gene) are shown in lanes 5 and 6.

$\mathrm{Na}_{2} \mathrm{HPO}_{4}(\mathrm{pH} 7 \cdot 2$ ), $0 \cdot 25 \mathrm{~mol} / 1 \mathrm{NaCl}, 7 \%$ SDS, $1 \mathrm{mmol} / 1 \mathrm{EDTA}, 10 \%$ PEG 6000 , and $100 \mathrm{mg} /$ $\mathrm{ml}$ boiled salmon sperm DNA) with constant agitation. After washing the membrane at $65^{\circ} \mathrm{C}$ for three $\times 30$ minutes in $2 \times \mathrm{SSC} / 0 \cdot 1 \% \mathrm{SDS}$, $1 \times \mathrm{SSC} / 0 \cdot 1 \% \mathrm{SDS}$, and $0.3 \times \mathrm{SSC} / 0 \cdot 1 \% \mathrm{SDS}$, respectively, it was autoradiographed between two intensifying screens at $-70^{\circ} \mathrm{C}$ for one to three days.

\section{Results}

The two types of inversions, involving either of the two distal A gene copies as described by Lakich et $a l^{9}$ and Naylor et $a l^{10}{ }^{10}$ were also detected in this study. An example of Southern blot analysis on $B c l I$ digested DNA of patients and carriers is shown in fig 1 . The normal pattern of $B c l$ restriction fragments consists of three bands of $21 \cdot 5,16$, and $14 \mathrm{~kb}$ (lanes 1,4 and 7), while the $B c l$ pattern of patients carrying a recombination product with the most distal A gene (inversion type 1) shows bands of $20,17 \cdot 5$, and $14 \mathrm{~kb}$ (lane 3 ). In patients where the more proximal A gene is involved (inversion type 2) bands of 20,16 , and $15.5 \mathrm{~kb}$ are found (lane 5). Carriers show the normal as well as the inversion restriction fragments (lanes 2 and 6).

Southern blot analysis of 177 unrelated Dutch haemophilia A cases showed an inversion in 57 out of 100 patients with severe disease $(57 \%)$, as well as in two out of 26 patients with moderately severe disease $(8 \%)$ (table 1). As expected, an inversion was not detected in any of the patients with mild haemophilia A, and inversions were found in three out of 14 cases for which the coagulation data

Table 1 Result of the inversion screening in 177 Dutch unrelated haemophilia $A$ patients

\begin{tabular}{lll}
\hline $\begin{array}{l}\text { Type of haemophilia } \\
A\end{array}$ & No of patients tested & $\begin{array}{l}\text { No of patients with } \\
\text { inversion }\end{array}$ \\
\hline Severe & 100 & 57 \\
Moderate & 26 & 2 \\
Mild & 37 & 0 \\
Unknown & 14 & 3 \\
Total & 177 & 62 \\
\hline
\end{tabular}

of the patients were not available. The majority $(85 \%)$ of the inversions showed a recombination with the most distal A gene (type 1), while a minority $(15 \%)$ have recombined with the more proximal A gene (type 2). In order to determine what the influence of this additional direct mutation detection is on both carrier detection and prenatal diagnosis, all relevant and available family members of the index patients were analysed for the presence of the inversion.

\section{IMPROVEMENT OF CARRIER DETECTION IN} FAMILIAL SITUATIONS

In families with multiple haemophilia A patients, carrier status and prenatal diagnosis can usually be determined by haplotype analysis. The availability of polymorphic, intragenic markers (for example, CA repeats) gives a reliability for this type of analysis of more than $99 \% .{ }^{1213}$ In only nine out of the 30 families with multiple haemophilia A patients in which an inversion was found, carrier detection by direct analysis of the inversion improved significantly (table 2 ). Fourteen women were confirmed to be carriers, of whom two already had a $95 \%$ risk of being a carrier by haplotype analysis. Two women were confirmed to be non-carriers after inversion analysis. For one carrier, who was uninformative by haplotype analysis, prenatal diagnosis can now be offered. This again illustrates the high informativeness of the polymorphic markers used for haplotype analysis in haemophilia $\mathrm{A}$.

\section{IMPROVEMENT OF CARRIER DETECTION IN} ISOLATED CASES

In families with an isolated patient, haplotype analysis may reliably exclude carrier status. However, if the at risk haplotype is transmitted, carrier status may or may not be present. In this type of family carrier detection can be improved considerably by determination of the

Table 2 Improvement of carrier status assessment in nine out of 30 families with multiple haemophilia $A$ patients in which an inversion was found

\begin{tabular}{ll}
\hline Carrier status after inversion analysis & No of women \\
\hline Carrier* & 14 \\
Non-carriert & 2 \\
Informative for prenatal diagnosis & 1 \\
\hline
\end{tabular}

* In two cases the probability of being a carrier was $95 \%$ by haplotype analysis.

t In one case the probability of being a non-carrier was $95 \%$ by haplotype analysis.

Table 3 Improvement of carrier status assessment in 32 families with an isolated haemophilia $A$ patient with an inversion involving 98 applicants

\begin{tabular}{lll}
\hline & Carriers & Non-carriers \\
\hline $\begin{array}{l}\text { Haplotype analysis only } \\
\begin{array}{l}\text { Inversion analysis of possible } \\
\text { carriers }(\mathrm{n}=70)\end{array}\end{array}$ & $70^{*}$ & $28 \dagger$ \\
\hline
\end{tabular}

* In eight cases the probability of being a carrier was $95 \%$ by haplotype analysis.

f In nine cases the probability of being a non-carrier was $95 \%$ by haplotype analysis. 

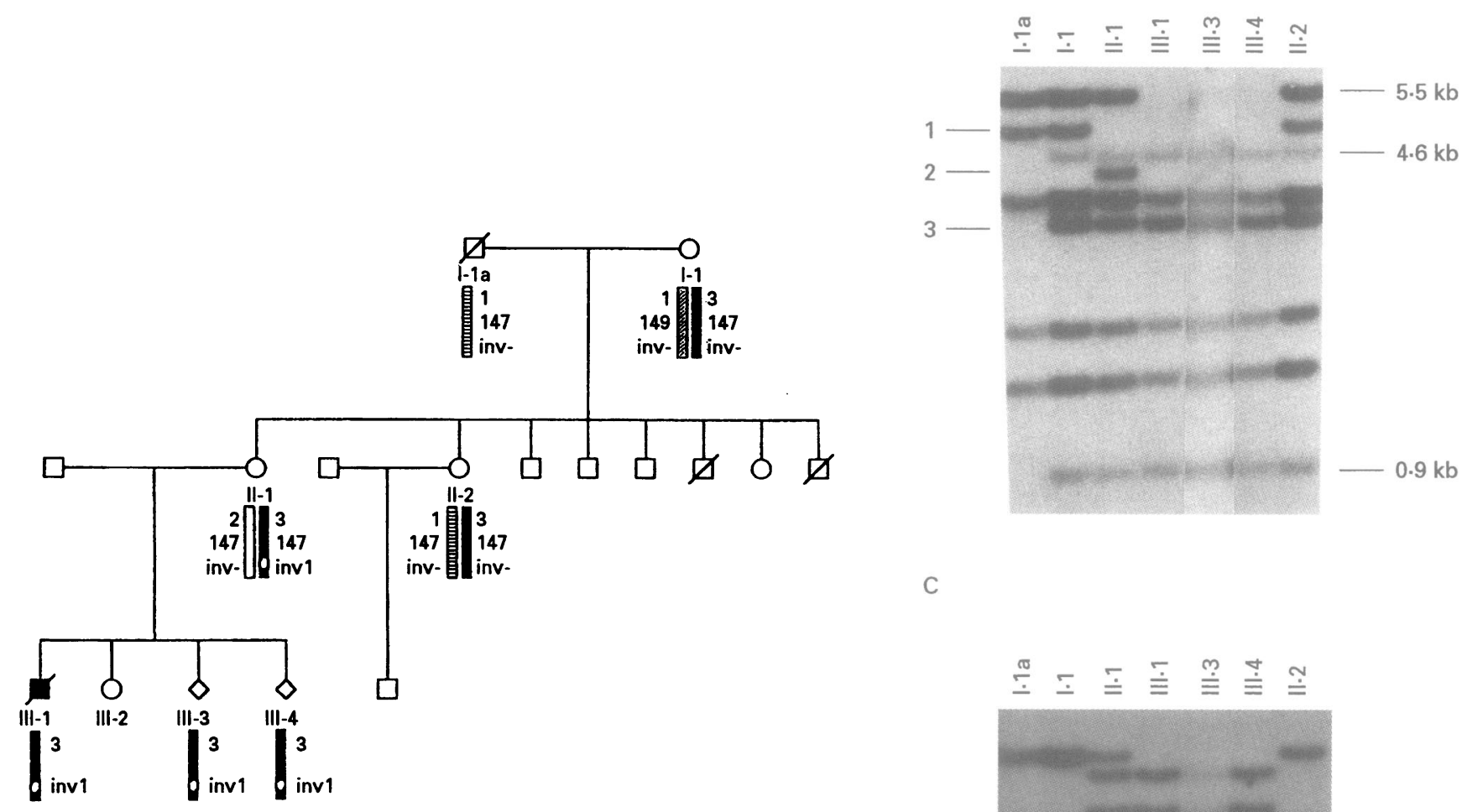

Figure 2 Pedigree and Southern blot analysis of a family with a grandmaternal origin of the inversion. (A) The pedigree shows that the inversion segregates with the grandmaternal haplotype and that the mother of the patient must have had a different father. Markers used for haplotype analysis: ST14/TaqI alleles 1, 2, 3; (CA) nepeat in intron 13 alleles 147, 149; inversion with most distal A gene inv1; no inversion present, inv-. (B) Southern blot analysis of TaqI digested DNA and hybridisation with ST14. Besides the indicated alleles, in all but one subject the $5.5 \mathrm{~kb}$ band divides into a $4.6 \mathrm{~kb}$ and $a 0.9 \mathrm{~kb}$ band. (C) Southern blot analysis of BclI digested DNA and hybridisation with the F8A probe. The mother (II.1) has the two extra fragments, indicating the inversion, which is also seen in the patient (III·1) and the two fetuses (III·3 and III·4). The numbers above the lanes correspond to the numbers given in the pedigree.

inversion. Table 3 shows the results of carrier detection in 32 families of isolated patients with an inversion. In these families, involving 70 possible carriers as determined by haplotype analysis, carrier status could now be established with certainty. Of the 70 women tested for the presence of the inversion, 44 turned out to be carriers and 26 were non-carriers. For 28 noncarriers by haplotype analysis, including nine women who had a 5\% risk left owing to the chance of a recombination with the extragenic markers, inversion analysis confirmed their non-carrier status. All mothers of patients who were available for analysis (25 out of 32) carried the inversion.

In 10 families with an isolated patient, a sufficient number of subjects was available to establish the grandpaternal origin of the mutation. In one family the mutation originated from the grandmother, as illustrated in fig 2 . The patient and his mother carried the inversion, which was not present in his grandparents and maternal aunt. Haplotype analysis showed a ST14 allele in the patient's mother, which is neither present in her father nor in her mother, indicating non-paternity. The in- version type 1 segregates with the grandmaternal allele. Both the patient and the two fetuses from earlier tests showed the inversion type 1 , as well as the grandmaternal ST14 allele. This makes it unlikely that the inversion is of grandpaternal origin, for which one would need to postulate three recombination events.

An example of carrier detection improvement within a family with an isolated patient with severe haemophilia $A$ is shown in fig 3. In this family, haplotype analysis showed the presence of the grandpaternal haplotype in the patient, and thus his mother and his three maternal aunts carry the at risk haplotype, as well as his sister. Because coagulation data gave no additional information, it was not possible to distinguish whether the mutation originated from the patient's mother or his grandfather. However, Southern blot analysis showed an inversion type 1 in the patient, as well as in both his mother and sister who therefore are carriers of haemophilia A. Neither his grandmother nor his three maternal aunts had the inversion and are therefore not carriers, indicating that the mutation was of grandpaternal origin. 

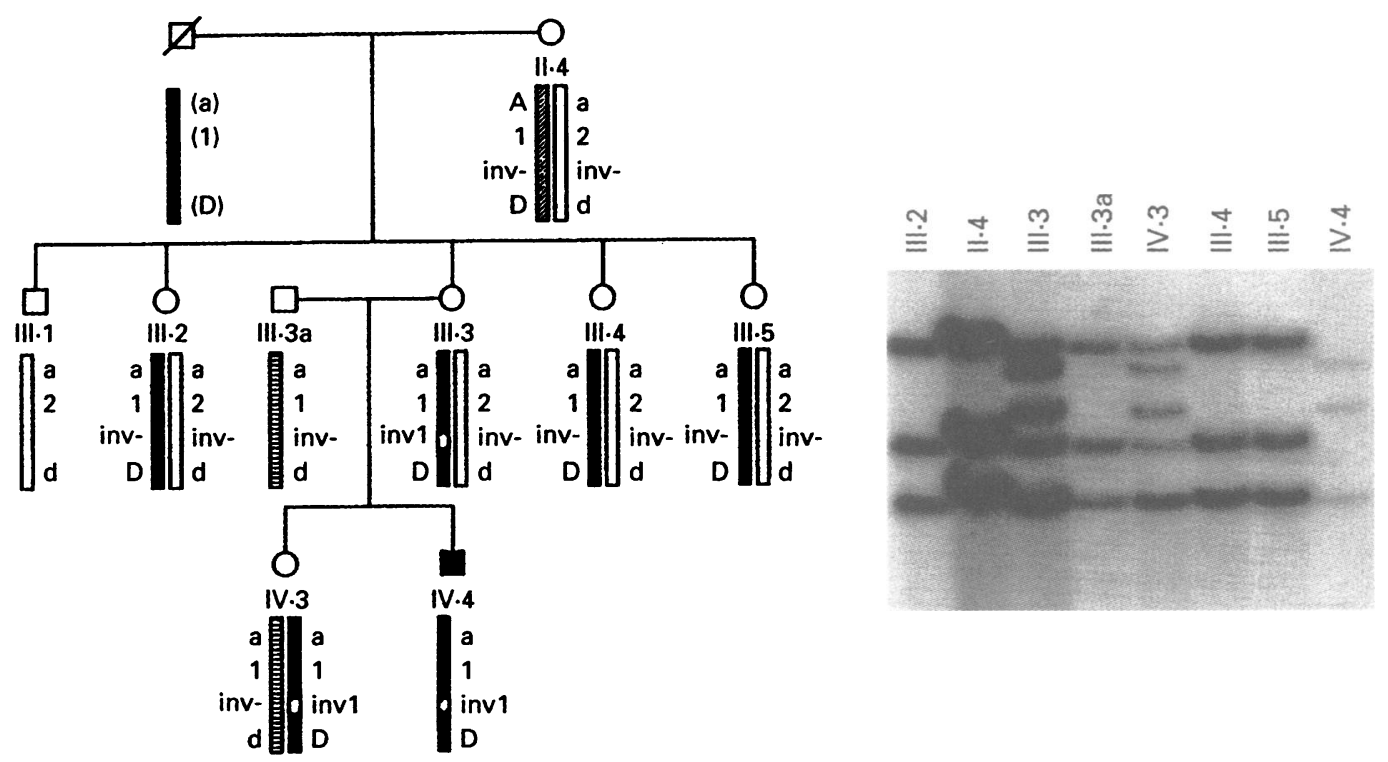

Figure 3 Pedigree and Southern blot analysis of a family with an isolated haemophilia $A$ patient. $(A)$ The pedigree shows that the mutation is of grandpaternal origin and that the carrier status for the mother, maternal aunts, and sister of the patient can now be determined. Markers used for haplotype analysis: DX13/BglII alleles $A, a$; ST14/TaqI alleles 1,$2 ; F 8 A / X b a I+K p n I$ alleles $D$, $d$; no inversion found, inv-; inversion with most distal $A$ gene, inv1. (B) Southern blot analysis of BclI digested DNA and hybridisation with the F8A probe for all relevant family members is shown. The numbers above the lanes correspond to the numbers given in the pedigree. The mother (III.3) and sister (IV·3) both have the two extra fragments indicating the inversion, which is also seen in the patient $(I V \cdot 4)$.

\section{Discussion}

Analysis of our patient material confirmed the presence of an inversion as the cause of haemophilia A in about $50 \%$ of the severely affected patients. The observation of the inversion in two patients with moderately severe haemophilia deserves some comment. Considering the profound disruption of the gene by the inversion, it is difficult to imagine that transcription and translation could result in any functional factor VIII. Consequently we are inclined to think that the classification as moderately severe disease in these patients is the result of the difficulty of reliably measuring factor VIII concentration below 2 or $3 \%$ of normal. In fact, of the two patients, one has coagulation data on the borderline of severe and moderate, but could clinically be described as having severe haemophilia (personal communication). The second patient, however, is clinically classified as more moderately affected. This implies that it is worthwhile to screen every patient for the presence of an inversion, regardless of the severity of the disease.

The possibility of direct detection of the disease causing mutation greatly improves carrier status assessment in almost all the families with an isolated haemophilia A patient. In addition, in a few carriers who were uninformative by haplotype analysis, the detection of an inversion now allows prenatal diagnosis. For carriers with an inversion who are also informative for the PCR based polymorphic intragenic markers, two diagnostic strategies for prenatal diagnosis can be followed. Either the chorionic villi DNA can be analysed by Southern blotting for the presence of an inversion, which is very reliable $(\sim 100 \%)$ but will take about two weeks, or the chorionic villi DNA can be analysed by PCR which takes only a few days and is also highly reliable ( $>99 \%)$. Which of the two strategies will be chosen can be decided for each individual case.

In all but one case the mutation is of (grand)paternal origin, which confirms the findings of Rossiter et al, ${ }^{18}$ who reported that the inversions originate almost exclusively in male germ cells. This suggests that the presence of only one $\mathrm{X}$ chromosome during meiosis enhances the chance of intrachromosomal recombination between the A gene in the FVIII gene and one of the telomeric A genes, causing inversion of the intervening DNA. If the origin of FVIII inversions is mainly restricted to male meiotic events, this implies that most or all mothers of isolated patients with an inversion will be a carrier, which is confirmed by our data. Furthermore, since the meiotic event will not lead to germinal mosaicism, the recurrence risk for grandfathers who once transmitted a de novo inversion will be very low or even back to the population level. To confirm confinement of inversion events to meiosis, more data are needed, especially to prove that germinal mosaicism does not occur in de novo inversion cases. This is in contrast to deletions and possibly point mutation events for which germinal mosaicism has been described. ${ }^{1920}$ Until now no germinal mosaicism has been detected in the three de novo inversion cases for which sufficient haplotype data from family members were available. An international collection of extensively haplotyped de novo inversion cases will be needed to prove or reject the hypothesis that this type of mutation event is meiotic. 
The majority of the inversions in the Dutch severe haemophilia A patients showed a recombination with the most distal A gene (85\%), while a minority had recombined with the more proximal A gene (15\%), which is in agreement with Lakich et al. ${ }^{9}$

In our group of inversion patients, we could not confirm the observation by Goodeve et $a l^{21}$ that the presence of an inversion is correlated with the absence of inhibitor development. The fact that seven out of $30(23 \%)$ of our inversion patients developed inhibitors is more in agreement with the assumption that the absence of the factor VIII protein predisposes to inhibitor development, as postulated by several authors. ${ }^{22} 23$

In conclusion, the inversion detection not only provides a powerful diagnostic tool, but it also makes carrier detection and prenatal diagnosis feasible in families with severe haemophilia $\mathrm{A}$ that are uninformative for haplotype analysis.

We thank the patients and their families for donating extra blood samples and the genetic counsellors and the Dutch Haemophilia Society (NVHP) for the referral of the counsellees and their families. We are grateful to Mrs $H$ van DiemenHoman for the organisation of the family studies.

1 Stites DP, Hershgold EJ, Perlman JD, Fudenberg HH Factor VIII detection by hemagglutination inhibition: he-
mophilia A and von Willebrand's disease. Science 1971 , 171:196-7.

2 Smit C, Rosendaal FR, Varekamp I, et al. Physical condition, longevity and social performance of Dutch haemophiliacs 1972-1985. BMf 1989;298:235-8.

3 Gitschier J, Wood WI, Goralka TM, et al. Characterization of the human factor VIII gene. Nature 1984;312:326-30.

4 Wood WI, Capon DJ, Simonsen CC, et al. Expression of active human factor VIII from recombinant DNA clones. Nature 1984;312:330-7.

5 Toole JJ, Knopf JL, Wozney JM, et al. Molecular cloning of a cDNA encoding antihaemophilic factor. Nature 1984; 312:342-7.

6 Tuddenham EGD, Cooper DN, Gitschier J, et al. Haemophilia A: database of nucleotide substitutions, de- letions, insertions and rearrangements of the factor VIII gene. Nucleic Acids Res 1991;19:4821-33.

7 Higuchi M, Kazazian HH, Kasch L, et al. Molecular characterization of severe hemophilia $A$ suggests that about half the mutations are not within the coding regions and splice junctions of the factor VIII gene. Proc Natl Acad Sci USA 1991;88:7405-9.

8 Naylor JA, Green PM, Rizza CR, Giannelli F. Analysis of factor VIII mRNA reveals defects in everyone of 28 haemophilia A patients. Hum Mol Genet 1993;2:11-17.

9 Lakich D, Kazazian HH, Antonarakis SE, Gitschier J. Inversions disrupting the factor VIII gene are a common cause of severe haemophilia A. Nature Genet 1993;5:23641 .

10 Naylor J, Brinke A, Hassock S, Green PM, Giannelli F Characteristic mRNA abnormality found in half the patients with severe haemophilia $\mathrm{A}$ is due to large DNA inversions. Hum Mol Genet 1993;2:1773-8.

11 Bröcker-Vriends AHJT, Briët E, Kanhai HHH, et al. First trimester prenatal diagnosis of haemophilia A: two years' experience. Prenat Diagn 1988;8:411-21.

12 Lalloz MRA, McVey JH, Pattinson JK, Tuddenham EGD. Haemophilia A diagnosis by analysis of a hypervariable dinucleotide repeat within the factor VIII gene. Lance 1991;338:207-11.

13 Lalloz MRA, McVey JH, Michaelides K, Tuddenham EGD. Haemophilia A diagnosis by analysis of a novel dinucleotide tandem repeat sequence within the factor VIII gene. Br $\mathcal{F}$ Haematol 1992;80:3A.

14 Bröcker-Vriends AHJT, Briët E, Wuadt R, et al. Genotype assignment of haemophilia $A$ by use of intragenic and extragenic restriction fragment length polymorphism. Thromb Haemost 1987;57:131-6.

15 Peake IR, Lillicrap DP, Boulyjenkov V, et al. Haemophilia: strategies for carrier detection and prenatal diagnosis. Bull WHO 1993;71:429-58.

16 Miller SA, Dykes DD, Polesky HF. A simple salting out procedure for extracting DNA from human nucleated cells. Nucleic Acids Res 1988;16:1215.

17 Sambrook J, Fritsch EF, Maniatis T. Molecular cloning: a laboratory manual, 2nd ed. New York: Cold Spring Harbor Laboratory Press, 1989.

18 Rossiter JP, Young M, Kimberland ML, et al. Factor VIII gene inversions causing severe hemophilia A originate almost exclusively in male germ cells. Hum Mol Genet 1994;3:1035-9.

19 Bröcker-Vriends AHJT, Briët E, Dreesen JCFM, et al. Somatic origin of inherited haemophilia A. Hum Genet 1990; 85:288-92.

20 Bakker E, Veenema H, Den Dunnen JT, et al. Germinal mosaicism increases the recurrence risk for 'new' Duchenne muscular dystrophy mutations. $¥$ Med Genet 1989 ; 26:553-9.

21 Goodeve AC, Preston FE, Peake IR. Factor VIII gene rearrangements in patients with severe haemophilia $A$. rearrangements in patient
Lancet 1994;343:329-30.

22 Ljung RCR. Intron 22 inversions and haemophilia. Lancet 1994;343:791.

23 Tizzano EF, Altisent $C$, Tusell J, Domènech $M$, Baiget $M$. Intron 22 inversions and haemophilia. Lancet 1994;343: 792. 